\title{
Treatments of Non-parasitic Giant Hepatic Cysts
}

\author{
NAOFUMI ERIGUCHI, SHIGEAKI AOYAGI, TSUYOSHI TAMAE, NAOMITSU KANAZAWA, \\ JUN NAGASHIMA, HIROYUKI HORIUCHI, SHINJI UCHIDA AND MAMORU HIRAKI
}

\author{
Department of Surgery, Kurume University School of Medicine, \\ Kurume 830-0011, Japan
}

\begin{abstract}
Summary: This retrospective study presents the results of surgical treatments for large cyst of the liver over $10 \mathrm{~cm}$ in diameter in 9 patients diagnosed and treated at Kurume University Hospital. There were 8 women and 1 man, with an average age of 71.6 years. Although the chief complaints were abdominal pain or fullness, 1 had obstructive jaundice due to biliary compression by a large cyst. Cyst size ranged from $10 \mathrm{~cm}$ to $27 \mathrm{~cm}$. There are several treatment modalities for giant hepatic cyst, such as cyst resection, unroofing, and sclerotherapy after cyst drainage. Operative procedures in the patients reported here were surgical resection of the liver cyst in 3 patients, unroofing with ethanol sclerotherapy in 1 patient and laparoscopic treatment in 2 patients. Sclerotherapy after percutaneous transhepatic cyst drainage was performed in 3 patients because their general condition was poor. There were no postoperative complications among these patients. Costs varied among the patients and depended mainly on the method of treatment and period of hospital stay. We discuss operative procedures and costs of treatment of each patient and review the literature.
\end{abstract}

Key words giant hepatic cyst, sclerotherapy, unroofing, percutaneous transhepatic cyst drainage

\section{INTRODUCTION}

Congenital hepatic cysts are usually asymptomatic and require no treatment, but occasionally they may become large enough to compress adjoining organs. Drainage leads to relapse and surgery is the classical option. The treatment of giant hepatic cyst is still controversial. The instillation of various sclerosing agents such as ethanol, tetracycline or minocycline had been performed for giant hepatic cyst [1-4]. Surgical management is indicated when the cyst is very large, or when signs of rupture, biliary compression, complications of hemorrhage or infection, or cystic neoplasm are present [5].

\section{PATIENTS AND METHODS}

In this series, between January, 1995 and April, 2000, 9 patients were referred to our hospital for giant hepatic cyst. Histories were taken and physical examination, blood work, chest radiography, and abdominal imaging were performed in all patients.
The clinical records were retrospectively reviewed regarding patient demographics, clinical features, pathologic findings, operative details, outcomes, prognosis, and costs. All patients were followed up either by return visits or by telephone interviews.

\section{RESULTS}

Characteristics of the 9 patients are given in Table 1. Our patients consisted of 8 women and 1 man ranging in age from 66 to 79 years, with a median age of 71.6 years. Chief complaints of these patients were abdominal pain in 3 patients, abdominal fullness in 3, abdominal pain with jaundice in 1, abdominal pain with fever in 1 , and back pain in 1 patient.

As for the operative procedures, laparoscopic unroofing was performed in 2 patients, and lobectomy in 3 patients who were diagnosed as cystic neoplasm or intracystic bleeding. The instillation of various sclerosing agents such as ethanol or minocycline was performed in 3 patients because surgical 
TABLE 1.

Clinical summary

\begin{tabular}{|c|c|c|c|c|c|c|c|}
\hline No. & Age/sex & Chief complaint & Preoperative diagnosis & $\begin{array}{l}\text { Operative procedures, } \\
\text { sclerosing agents }\end{array}$ & Size $(\mathrm{cm})$ & Outcome & Hospital stay \\
\hline 1 & $70 / \mathrm{M}$ & $\begin{array}{l}\text { Jaundice, } \\
\text { abdominal pain }\end{array}$ & Obstructive jaundice & PT Cyst D, minocycline & $18 \times 15$ & Symptom-free & 79 days \\
\hline 2 & $75 / \mathrm{F}$ & Abdominal pain & Liver cyst & PT Cyst D, ethanol & $11 \times 10$ & Symptom-free & 45 days \\
\hline 3 & $69 / F$ & Abdominal pain & Liver cyst & Lapa. unroofing, ethanol & $15 \times 10$ & Symptom-free & 8 days \\
\hline 4 & $68 / \mathrm{F}$ & Abdominal fullness & $\begin{array}{l}\text { Cystadenocarcinoma } \\
\text { suspect }\end{array}$ & Right lobectomy & $17 \times 12$ & Symptom-free & 44 days \\
\hline 5 & $70 / \mathrm{F}$ & Abdominal pain & $\begin{array}{l}\text { Cystadenoma } \\
\text { or carcinoma suspect }\end{array}$ & Right lobectomy & $18 \times 15$ & Symptom-free & 20 days \\
\hline 6 & $79 / \mathrm{F}$ & Back pain & Liver cyst & PT Cyst D, ethanol & $10 \times 8$ & Symptom-free & 33 days \\
\hline 7 & $76 / \mathrm{F}$ & Abdominal fullness & Liver cyst & Lapa. unroofing, ethanol & $16 \times 11$ & Symptom-free & 8 days \\
\hline 8 & $66 / \mathrm{F}$ & Abdominal fullness & Liver cyst & Unroofing, ethanol & $14 \times 10$ & Symptom-free & 18 days \\
\hline 9 & $72 / \mathrm{F}$ & $\begin{array}{l}\text { Abdominal pain, } \\
\text { fever }\end{array}$ & Liver abscess & Left lobectomy & $27 \times 22$ & Symptom-free & 12 days \\
\hline
\end{tabular}

PT Cyst D: percutaneous transhepatic cyst drainage; Lapa.: under the laparoscopic technique

Hospital stay: period after treatment or surgical resection

intervention was considerably more invasive and because of their poor general condition.

Regarding the costs of treatment, surgical resection of the liver in patients without any complications required about $\$ 20,000$ and 20 days of hospitalization after treatments. Cystic drainage and instillation of drugs into the hepatic cyst cost about $\$ 10,000$ and required 40 days of hospitalization. Laparoscopic unroofing cost about $\$ 8,000$ and required 8 days of hospitalization.

Prognoses of these patients were favorable. All have had good clinical courses without recurrence at this time.

\section{DISCUSSION}

Cystic liver disease usually consists of solitary cysts, appears in adulthood and is more common in women. The female to male ratio is estimated to be 1.5:1 and cysts are symptomatic more often in women than in men [6,7]. Most cysts are detected incidentally by ultrasonography or computed tomography. Occasionally they become large enough to cause symptoms, most commonly pain in the right upper quadrant, abdominal distension, nausea and vomiting or early satiety, and may be complicated by biliary obstruction and jaundice [8]. The differential diagnosis includes neoplastic cysts, cystic dilation of extrahepatic ducts, infective cysts and familial polycystic liver disease. Symptomatic relief and confirmation of the non-malignant or infective state of the cyst was obtained by ultrasound-guided aspiration.
Regarding the treatments for giant hepatic cysts, three methods were applied. Surgical management for the cyst is indicated when signs of rupture, biliary compression, complications of hemorrhage or infection, or neoplastic findings are present. Although percutaneous ethanol injection is usually performed for large cysts, untoward effects such as fever and abdominal pain occur frequently. Furthermore, the rate of recurrence after treatment is very high, and recurrence has been seen from 2 weeks to 54 months after the therapy, usually in 10-18 months $[9,10]$. When instillation therapy is considered, it is essential that communication with the biliary tree is excluded by catheter sinogram or endoscopic retrograde cholangiography, and that there is no extravasation into the peritoneal cavity [11]. More recently, laparoscopic methods, including laser assisted excision, transhepatic fenestration and unroofing of cysts, have been reported; these methods have the attraction of a reduced length of stay in hospital and a potential decrease in morbidity [12-15]. As an easier form of therapy for giant hepatic cyst, laparoscopic fenestration was begun in $1991[13,16]$. This treatment reduces the postoperative hospital stay, and allows an earlier return to normal activity.

As for the costs of treatment of patients with giant hepatic cyst, laparoscopic surgery results in lower costs because the postoperative period of hospitalization is reduced [17].

In conclusion, we recommend laparoscopic unroofing in combination with ethanol or other sclerotherapy as a very good procedure for treatment 
of giant hepatic cysts because of low costs and short hospitalization. However, long-term follow-up is considered essential for evaluating methods of treatment.

\section{REFERENCES}

1. Davies CW, and McIntyre AS. Treatment of a symptomatic hepatic cyst by tetracycline hydrochloride instillation sclerosis. Eur J Gastroenterol Hepatol 1996; 8:173-175

2. Adachi K, Kamiya T, Nagao T, Ando T, Sui H et al. Giant hepatic cyst successfully treated with injection of a small amount of minocycline chloride: study cases. Nippon Naika Gakkai Zasshi (Jpn J Inter Med) 1997; 86:838-839. (in Japanese)

3. Yamada N, Shinzawa H, Ukai K, Makino N, Matsuhashi $\mathrm{T}$ et al. Treatment of symptomatic hepatic cysts by percutaneous instillation of minocycline hydrochloride. Dig Dis Sci 1994; 39:2503-2509.

4. Shimura J, Ukita $T$, Inoue $H$, Ishiguro J, Ogawa $\mathrm{S}$ et al. A case of biliary stenosis in polycystic liver improved by injection of minocycline hydrochloride to a hepatic cyst. Nippon Shokakibyo Gakkai Zasshi (Jpn J Gastroenterol) 2000; 97:1038-1042. (in Japanese)

5. Becker S. Cysts of the liver. In: Bockus Gastroenterology, ed. Berk JE, W.B.Saunders, Philadelphia, pp 3278-3287, 1985.

6. Benhamou JP, and Menu Y. Non-parasitic cystic diseases of the liver and intrahepatic biliary tree. In: Surgery of the Liver and Biliary Tract, ed. Blumgart LH, Churchill Livingstone, Edinburgh, pp 1197-1210, 1994.

7. Martin IJ, Mckinley AJ, and Currie EJ. Tailoring the management of nonparasitic liver cysts. Ann Surg 1998; 228:167-172.
8. Kanai T, Kenmochi T, Takabayashi T, Hangai N, Kawano $\mathrm{Y}$ et al. Obstructive jaundice caused by a huge liver cyst riding on the hilum: report of a case. Surg Today 1999; 29:791-794.

9. Trinkl W, Sassaris M, and Hunter FM. Nonsurgical treatment for symptomatic nonparasitic liver cyst. Am J Gastroenterol 1985; 11:907-911.

10. Andersson R, Jeppsson B, and Lunderquist A. Alcohol sclerotherapy of nonparasitic cysts of the liver. Br J Surg 1989; 76:254-255.

11. Schwartz DS, Gwertzman G, Kaleya RN, and Gliedman ML. Laparoscopic unroofing of multiple benign liver cysts with intraperitoneal drainage: a case report. Laparoscopic Surg 1994; 4:157-160.

12. Sanchez H, Gagner M, Rossi RL, Jenkins RL, Lewis WD et al. Surgical management of nonparasitic cystic liver disease. Am J Surg 1991; 161:113-119.

13. Paterson-Brown S, and Garden OJ. Laser-assisted laparoscopic excision of the liver cyst. Br J Surg 1991; 78:1047.

14. Tate JJT, Lau WY, and Li AKC. Transhepatic fenestration of liver cyst: a further application of laparoscopic surgery. Aust NZ J Surg 1994; 64:264-265.

15. Uchikoshi F, Ito N, Matsumoto K, Fukumoto $\mathrm{Y}$, and Kamiike W. Solitary liver cyst causing obstructive jaundice: report of a case treated with laparoscopic dome resection. Nippon Shokakigeka Gakkai Zasshi (Jpn J Gastroenterol Surg) 1997; 30:867-871. (in Japanese)

16. Iwase K, Takao T, Watanabe H, Tanaka Y, Kido T et al. Laparoscopic deroofing for symptomatic liver cysts: report of a case. Surg Today 1994; 24:641-643.

17. Tanaka S, Watanabe M, Akagi S, Sato S, Niigata M et al. Laparoscopic fenestration in combination with ethanol sclerotherapy prevents a recurrence of symptomatic giant liver cyst. Surg Laparosc Endosc 1998; 8:453-456. 